\title{
Oxygen tracer diffusion and surface exchange kinetics in $\mathrm{Ba}_{0.5} \mathrm{Sr}_{0.5} \mathrm{Co}_{0.8} \mathrm{Fe}_{0.2} \mathrm{O}_{3}-\delta$
}

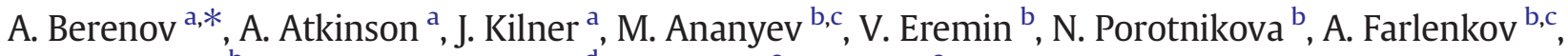 \\ E. Kurumchin ${ }^{\text {b }}$, H.J.M. Bouwmeester ${ }^{\mathrm{d}}$, E. Bucher ${ }^{\mathrm{e}}$, W. Sitte ${ }^{\mathrm{e}}$ \\ a Imperial College London, Exhibition Road, London SW7 2AZ, United Kingdom \\ b Institute of High Temperature Electrochemistry, UB RAS, Yekaterinburg, Russia \\ c Ural Federal University, Yekaterinburg, Russia \\ d Inorganic Membranes, Institute for Nanotechnology, Faculty of Science and Technology, University of Twente, P.O. Box 217, 7500 AE Enschede, The Netherlands \\ e Chair of Physical Chemistry, Montanuniversitaet Leoben, Franz-Josef-Strasse 18, A-8700 Leoben, Austria
}

\section{A R T I C L E I N F O}

\section{Article history:}

Received 13 June 2014

Received in revised form 24 September 2014

Accepted 29 September 2014

Available online 24 October 2014

\section{Keywords:}

Barium strontium iron cobaltate

Secondary-ion mass spectroscopy

Gas-phase analysis

Oxygen tracer diffusion

Oxygen tracer surface exchange

Solid oxide fuel cells

\begin{abstract}
A B S T R A C T
The oxygen tracer diffusion coefficient, $D_{b}{ }^{*}$, and the oxygen tracer surface exchange coefficient, $k$, were measured in $\mathrm{Ba}_{0.5} \mathrm{Sr}_{0.5} \mathrm{Co}_{0.8} \mathrm{Fe}_{0.2} \mathrm{O}_{3}{ }_{-}$(BSCF5582) over the temperature range of $310-800{ }^{\circ} \mathrm{C}$ and the oxygen partial pressure range of $1.3 \times 10^{-3}-0.21$ bar. Several measurement techniques were used: isotope exchange followed by depth profiling (IEDP) within individual single grains or line scanning (IELS) along the sample cross-section and gas-phase analysis (GPA). Surface exchange kinetics was initially found to be slow and presumably inhibited by the formation of a passivating layer on the sample surface. High temperature pre-anneals $\left(900-950{ }^{\circ} \mathrm{C}\right)$ changed the nature of this layer and enhanced surface exchange. Fast bulk oxygen diffusion and surface exchange kinetics were observed after high temperature pre-anneals within the temperature range studied. The activation energies for ${ }^{18} \mathrm{O}$ tracer diffusion and surface exchange at 0.21 bar were $0.72 \pm 0.05$ and $1.10 \pm 0.15 \mathrm{eV}$, respectively. The tracer diffusion coefficient showed weak dependence upon oxygen partial pressure, whereas the surface exchange coefficient exhibited strong oxygen partial pressure dependence. The microstructure of the samples (the porosity and grain size) had a profound effect on the measured tracer diffusion coefficient.
\end{abstract}

(c) 2014 Elsevier B.V. All rights reserved.

\section{Introduction}

Currently, there is a drive to lower the operating temperature of solid oxide fuel cells (SOFCs) to around $600{ }^{\circ} \mathrm{C}$ or below. $\mathrm{Ba}_{0.5} \mathrm{Sr}_{0.5} \mathrm{Co}_{0.8} \mathrm{Fe}_{0.2} \mathrm{O}_{3}-{ }_{\delta}$ (BSCF5582) has been shown to exhibit promising cathode performance in the temperature range of 500$600{ }^{\circ} \mathrm{C}[1]$. The material has a cubic perovskite structure with a large number of disordered oxygen vacancies [2]. In order to understand and further improve its performance, reliable data on the parameters of oxygen transport in BSCF ceramics, namely surface exchange coefficient, $k$, and bulk oxygen tracer diffusion coefficient, $D_{b}{ }^{*}$, are required.

It is generally accepted that tracer diffusion studies using the isotope exchange depth profiling (IEDP) method require specimens with the relative density greater than $95 \%$ [3] to ensure reliable data. In our preliminary studies the effects of processing parameters (e.g. sintering temperature, oxygen partial pressure, powder morphology) on the densification of BSCF were investigated in order to meet this requirement. However, no sintering conditions were found which could produce samples with sufficiently high relative density. Similarly, the

\footnotetext{
* Corresponding author. Tel.: +44 207594 6809; fax: +44 2075843194.

E-mail address: a.berenov@imperial.ac.uk (A. Berenov).
}

relative density of the BSCF membranes used for the oxygen permeation studies was in the range of $93-96 \%$, even when BN was used as a sintering aid [4]. Consequently, a method employing a focused ion beam (FIB) microscope equipped with a secondary-ion mass spectrometer (SIMS) attachment was used for depth profiling in selected fully dense regions in the present study.

Oxygen isotope exchange with gas-phase analysis (GPA) can be performed on porous specimens alleviating instrumental difficulties associated with the IEDP method and providing temperature and $\mathrm{pO}_{2}$ dependencies of the oxygen exchange and diffusion coefficients. During the GPA experiments the integrated sample response from both the bulk and grain boundaries leads to changes of the gas-phase composition. This could lead to ambiguity in the determination of the values of diffusion coefficients when the effect of the grain boundaries is not considered, or there is surface exchange that does not lead to the incorporation into the bulk lattice (e.g. of surface adatoms). In the latter case, the redistribution between the concentration of ${ }^{16} \mathrm{O}_{2},{ }^{18} \mathrm{O}_{2}$ and ${ }^{16} \mathrm{O}^{18} \mathrm{O}$ occurs whereas ${ }^{18} \mathrm{O}$ gas-phase fraction remains constant. Therefore, it is important to compare the results of the measurements of oxygen surface exchange and diffusion obtained by analysing the changes of gas-phase composition (GPA) and localised diffusion profiles within the individual grains (IEDP). 


\section{Experimental}

The synthesis of the $\mathrm{Ba}_{0.5} \mathrm{Sr}_{0.5} \mathrm{Co}_{0.8} \mathrm{Fe}_{0.2} \mathrm{O}_{3}-\delta$ (BSCF5582) specimens used in this work (samples A, B and C) has been reported previously [5, 6 ] and the summary of the preparation conditions is given in Table 1. Powder X-ray diffraction (XRD) patterns were recorded on a Philips 1710 diffractometer using monochromatic $\mathrm{Cu}-\mathrm{K} \alpha$ radiation. Si was used as an external standard. The GSAS program [7] was used to calculate the lattice parameters. The sample morphology was examined by scanning electron microscopy (SEM) with energy dispersive X-ray spectroscopy (EDX) attachment (JEOL JSM-5300 and JEOL JSM5900LV).

The parameters of oxygen tracer diffusion were determined by two experimental techniques. The first is isotope exchange in an ${ }^{18} \mathrm{O}$ enriched atmosphere followed by secondary-ion mass spectroscopy (SIMS) depth profiling by sputtering or line scanning [3]. The second is the isotope exchange method with gas-phase analysis using a static circulation setup [8].

For the first experimental technique, the specimens were polished to $1 / 4 \mu \mathrm{m}$ using a diamond spray polishing compound. The samples were pre-annealed in research grade natural isotopic oxygen (99.9995\%) at high temperature $\left(900-950^{\circ} \mathrm{C}\right)$ for $1 \mathrm{~h}$ in order to modify the surface layer (as discussed below) and then under the same conditions as the subsequent isotope exchange to ensure that the samples were in chemical equilibrium with their surroundings and to remove surface damage caused by the polishing. The isotope exchanges were carried out in an ${ }^{18} \mathrm{O}$-enriched atmosphere (29-35\% of ${ }^{18} \mathrm{O}$ isotope) at a nominal pressure of $0.21 \mathrm{bar}$, in the temperature range of $310-590{ }^{\circ} \mathrm{C}$. The duration of the anneals was varied from 8 min to $2 \mathrm{~h}$. Temperature-time profiles for the anneals were recorded and used in the calculation of a corrected annealing time, as discussed by De Souza [9].

Local isotope concentration profiles were measured by the isotope exchange depth profiling technique (IEDP) using a FIB (FEI-200) microscope equipped with the SIMS using a $30 \mathrm{keV} \mathrm{Ga}^{+}$primary beam at normal incidence. Profiles were obtained within the individual grains of the sample with sufficiently large grain size (sample A) by sputtering the craters of up to $10 \times 10 \mu \mathrm{m}$. Intensities of negative ions $\left({ }^{16} \mathrm{O}^{-}\right.$and ${ }^{18} \mathrm{O}^{-}$) were recorded as a function of the sputtering time. The depth of the craters was measured by a surface profilometer (Zygo Maxim GP200) using filtered white light optical interferometry. The sputtering time was converted into depth assuming a constant sputtering rate as discussed below. The isotope concentration profiles in the sample with small grain size (sample B) were measured along the specimen cross-section by the isotope exchange line scanning technique (IELS) using an Atomika 6500 instrument with $5 \mathrm{keV} \mathrm{Ar}^{+}$primary beam with a diameter of $13 \mu \mathrm{m}$.

With the present experimental setup two sets of boundary conditions were used for the solution of the diffusion equation, depending on the values of the bulk oxygen tracer diffusion coefficient $\left(D_{b}{ }^{*}\right)$, diffusion time $(t)$, and sample thickness $(l)$. De Souza et al. [10] have pointed out that if $4 \sqrt{D_{b}^{*}} t>l / 2$ the solution for diffusion into a finite sheet of thickness $l$ should be used, otherwise the process can be regarded as diffusion into a semi-infinite medium.

The solution for the isotope tracer diffusion into a semi-infinite medium is given by the following equation [11]:

$$
\begin{aligned}
C^{\prime}(x, t) & =\frac{C(x, t)-C_{b g}}{C_{g}-C_{b g}} \\
& =\operatorname{erfc}\left[\frac{x}{2 \sqrt{D_{b}^{*} t}}\right]-\left[\exp \left(\frac{k x}{D_{b}^{*}}+\frac{k^{2} t}{D_{b}^{*}}\right) \times \operatorname{erfc}\left(\frac{x}{2 \sqrt{D_{b}^{*} t}}+k \sqrt{\frac{t}{D_{b}^{*}}}\right)\right]
\end{aligned}
$$

where $C^{\prime}(x, t)$ is the normalised concentration of ${ }^{18} \mathrm{O}, C(x, t)$ is the tracer concentration as a function of depth $(x)$ and diffusion time $(t), C_{b g}$ is the background abundance of ${ }^{18} \mathrm{O}, C_{g}$ is the ${ }^{18} \mathrm{O}$ concentration in the gas, $D_{b}{ }^{*}$
Table 1

Preparation conditions of studied samples.

\begin{tabular}{lllll}
\hline Sample & $\begin{array}{l}\text { Sintering } \\
\text { conditions }\end{array}$ & $\begin{array}{l}\text { Thickness, } \\
\mathrm{mm}\end{array}$ & $\begin{array}{l}\text { Relative density, } \\
\%\end{array}$ & $\begin{array}{l}\text { Grain size, } \\
\mu \mathrm{m}\end{array}$ \\
\hline $\mathrm{A}$ & $1130^{\circ} \mathrm{C}, 4 \mathrm{~h}$ & 0.59 & 96 & $57 \pm 8$ \\
$\mathrm{~B}$ & $1000^{\circ} \mathrm{C}, 15 \mathrm{~h}$ & 0.58 & 92 & $6 \pm 2$ \\
$\mathrm{C}$ & $1050{ }^{\circ} \mathrm{C}, 3 \mathrm{~h}$ & 0.81 & 94 & $9 \pm 1$ \\
\hline
\end{tabular}

is the bulk oxygen tracer diffusion coefficient, and $k$ is the surface exchange coefficient. The solution for the isotope tracer diffusion into a finite sheet of thickness $l$ is given by [11]:

$C^{\prime}(x, t)=\frac{C(x, t)-C_{b g}}{C_{g}-C_{b g}}=1-\sum_{n=1}^{\infty} \frac{2 L \cos \left(2 \beta_{n} x / l\right) \exp \left(-4 \beta_{n}^{2} D_{b}^{*} t / l^{2}\right)}{\left(\beta_{n}^{2}+L^{2}+L\right) \cos \beta_{n}}$

where the $\beta_{n}$ 's are the positive roots of

$\beta \tan \beta=L$

and

$L=l \times \frac{k}{D_{b}^{*}}$

The natural isotopic abundance of ${ }^{18} \mathrm{O}$ was measured on an unexchanged sample. Although the measured ${ }^{18} \mathrm{O}$ isotope fraction was 0.003 which is slightly higher than the accepted natural abundance value of 0.002 , the closeness of the values is acceptable considering the fact that the chamber pressure in the FIB instrument has only reached $5.5 \times 10^{-7}$ mbar [12] which can make significant difference to the measured ${ }^{18} \mathrm{O}$ fraction due to residual gases. The fraction of ${ }^{18} \mathrm{O}$ in the exchange gas was measured by SIMS analysis of the $\mathrm{SiO}_{2}$ layer grown on a $\mathrm{Si}$ wafer oxidised in the ${ }^{18} \mathrm{O}_{2}$ atmosphere at $1100{ }^{\circ} \mathrm{C}$ for $16 \mathrm{~h}$. Values of $D_{b}{ }^{*}$ and $k$ were obtained by a non-linear least square fit of Eq. (1) or (2) to the experimental data. The duration of the isotope exchanges was corrected using temperature-time profiles recorded in order to take into account the sample cooling [13].

The experimental setup for the gas-phase analysis technique consisted of a gas circuit with a quartz reactor containing the sample. The isotope composition of the gas phase $\left(83.5 \%\right.$ of ${ }^{18} \mathrm{O}$ isotope $)$ circulated through the setup monitored by an Agilent $5973 \mathrm{~N}$ quadrupole mass spectrometer. The total volume of the gas circuit within the reactor was $500 \mathrm{ml}$. This setup allows the oxygen isotope composition of the gas phase to be monitored in situ during the exchange experiments. Before the experiment the slab shaped sample $C$ was equilibrated at the required temperature and oxygen partial pressure. After the equilibration the reactor with the sample was isolated and oxygen enriched in the ${ }^{18} \mathrm{O}$-isotope was introduced into the gas circuit. To prevent limitation due to gas diffusion a circulation pump was used.

The gas-solid exchange rate $(H)$, i.e. the number of oxygen atoms exchanging through unit surface area per unit time, and oxygen tracer diffusion coefficient $\left(D_{b}{ }^{*}\right)$ were calculated according to the model by Klier et al. [14] from the time dependence of the ${ }^{18} \mathrm{O}$-isotope fraction $(\alpha)$ in the gas phase. The fraction of ${ }^{18} \mathrm{O}$ isotope in the gas phase was calculated according to the following equation

$\alpha=\frac{N_{18}}{N_{18}+N_{16}}=\frac{C_{34}+2 C_{36}}{C_{34}+2 C_{36}+C_{34}+2 C_{32}}=\frac{1}{2} C_{34}+C_{36}$,

where $N_{18}, N_{16}, C_{32}, C_{34}$, and $C_{36}$ - are the numbers of ${ }^{18} \mathrm{O}$ and ${ }^{16} \mathrm{O}$ atoms and fractions of ${ }^{16} \mathrm{O}_{2},{ }^{16} \mathrm{O}{ }^{18} \mathrm{O}$ and ${ }^{18} \mathrm{O}_{2}$ molecules in a gas phase, respectively. 
The solution of tracer diffusion into the slab-type geometry is given by [14]

$\alpha(t)=\gamma_{0}+\left(\alpha^{0}-\alpha_{S}^{0}\right) \sum_{m=1}^{\infty} B_{m}^{-1} \times \exp \left(-\frac{D_{b}^{*} \beta_{m}^{2}}{L^{2}}\right)$

where $\gamma_{0}$ is the ${ }^{18} \mathrm{O}$ isotope fraction in the gas phase after equilibrium was established, $\alpha^{0}$ and $\alpha_{S}{ }^{0}$ are the ${ }^{18} \mathrm{O}$ isotope fraction in the gas phase and sample surface at $t=0$, and $L$ is the half thickness of the slab. The values of $B_{m}{ }^{\prime} s$ were calculated from the following equation

$$
\begin{aligned}
B_{m}= & \frac{1}{2}\left(1+\frac{N_{S}}{N_{g}}+\frac{N_{V}}{N_{g}}\right)+\beta_{m}^{2}\left[\frac{\left(N_{g} / 2+N_{S}+\left(N_{S}^{2} / 2 N_{g}\right)\right.}{N_{V}}+\frac{D_{b}^{*}}{H S L^{2}}\left(\frac{1}{2} N_{g}-N_{S}-N_{V}\right)\right]+ \\
& +\beta_{m}^{4}\left[\left(N_{S}+N_{V}\right) \frac{N_{g}\left(D_{b}^{*}\right)^{2}}{2(H S)^{2} L^{4}}-\left(N_{S}+N_{g}\right) \frac{N_{S} D_{b}^{*}}{N_{V} H S L^{2}}\right]+\beta_{m}^{6}\left[\frac{N_{S}^{2} N_{g}\left(D_{b}^{*}\right)^{2}}{2 N_{V}(H S)^{2} L^{4}}\right]
\end{aligned}
$$

where $N_{g}, N_{v}$, and $N_{S}$ are the number of oxygen atoms in the gas phase, in the volume of the oxide sample and on the surface of the sample, respectively; $S$ is the surface of the sample measured geometrically. $\beta_{m}$ are the positive roots of

$$
-\tan (\beta)=\frac{\beta\left(1+\left(N_{S} / N_{g}\right)-\beta^{2}\left(N_{S} D_{b}^{*} /\left(H S L^{2}\right)\right)\right)}{\left(N_{V} / N_{g}\right)-\beta\left(N_{V} D_{b}^{*} /\left(H S L^{2}\right)\right)}
$$

where $m$ - is the number of a root of the Eq. (8) which has the infinite number of roots due to a periodic nature of $\tan (\beta)$ function. The surface exchange coefficient, $k$, was calculated from the following equation

$k=H \frac{V_{O}}{N_{V}}=H \frac{M_{r}}{(3-\delta) N_{A} \rho}$

where $V_{O}$ - volume of the specimen, $M_{r}$ - molar mass, $\delta$ - oxygen nonstoichiometry, $N_{A}-$ Avogadro's constant, and $\rho$ - density. The data for the oxygen non-stoichiometry in BSCF5582 as a function of $T$ and $\mathrm{pO}_{2}$ [15] were used for the calculations of $k$.

\section{Results and discussion}

Prior to ${ }^{18} \mathrm{O}$ exchanges single phase cubic BSCF5582 perovskite was observed in all specimens (see Ref. [16] for samples A and B and Fig. 1 for sample C). The cubic lattice parameter of 3.98245(7) $\AA$ is in good agreement with the literature value [1]. After ${ }^{18} \mathrm{O}$ exchanges no impurity phases were detected by XRD except for sample A annealed at $544{ }^{\circ} \mathrm{C}$ for $25 \mathrm{~min}$ where several peaks belonging to hexagonal BSCF5582 phase

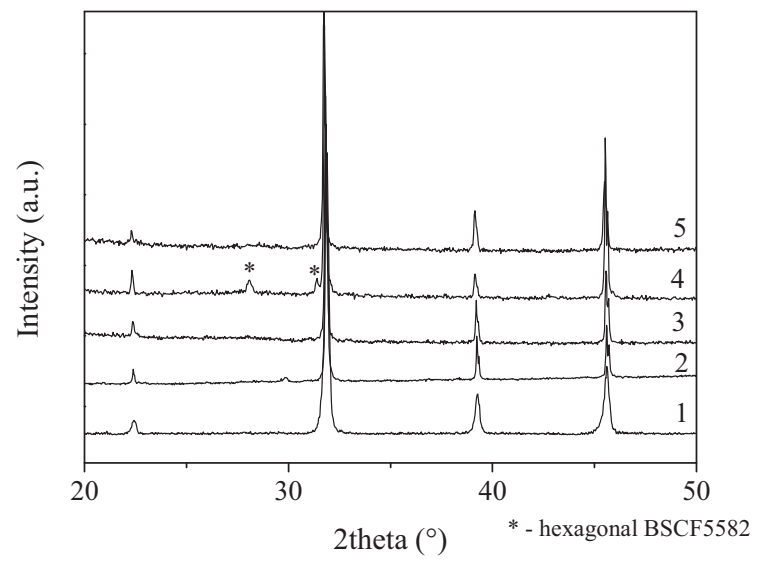

Fig. 1. XRD patterns of specimens before ${ }^{18} \mathrm{O}$ exchange (sample $\mathrm{C}(1)$ ) and after ${ }^{18} \mathrm{O}$ exchanges (sample A, $311^{\circ} \mathrm{C}, 20.4 \mathrm{~min}(2)$; sample B $444{ }^{\circ} \mathrm{C}, 877 \mathrm{~min}(3)$; sample A, $544{ }^{\circ} \mathrm{C}, 25.9 \mathrm{~min}(4)$; sample B $\left.594{ }^{\circ} \mathrm{C}, 68 \mathrm{~min}(5)\right)$. were observed. The co-existence of cubic and hexagonal BSCF5582 at the intermediate temperatures of $750-850{ }^{\circ} \mathrm{C}$ has been previously observed [17]. The estimated amount of the hexagonal phase was around $10 \mathrm{wt} . \%$. The SEM images of the specimens are shown in Fig. 2. Increasing the sintering temperature (Table 1) increased both the samples density and grain size. Significant porosity, which appeared to be at least partially interconnected, was observed in sample A. As a result the depth profiling technique within the individual grains was used for sample A, whereas the standard line scanning technique was used for sample B.

Several preliminary ${ }^{18} \mathrm{O}$ exchange experiments were carried out without a high temperature pre-anneal. Even though relatively long annealing times were employed $\left(25 \mathrm{~min}\right.$ at $590{ }^{\circ} \mathrm{C}$ (Fig. 3 ) and $2 \mathrm{~h}$ at $500{ }^{\circ} \mathrm{C}$ (not shown)), the measured ${ }^{18} \mathrm{O}$ fraction in the bulk was found

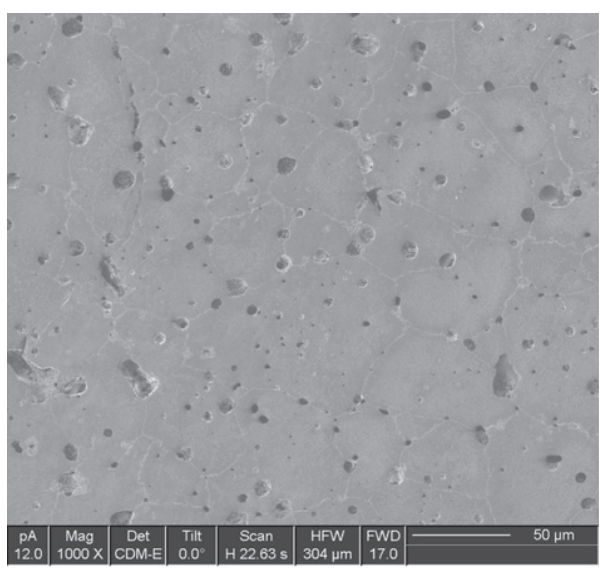

a)

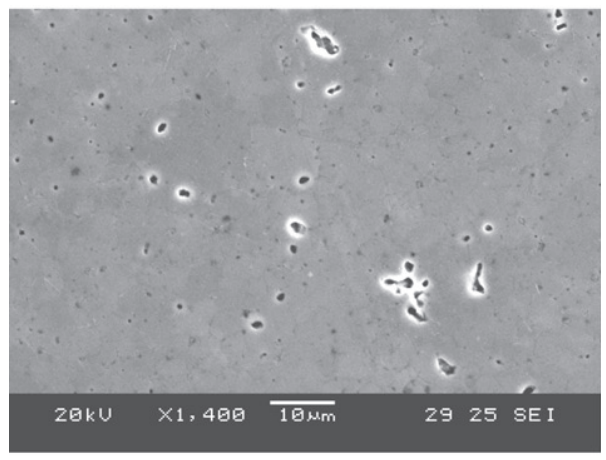

b)

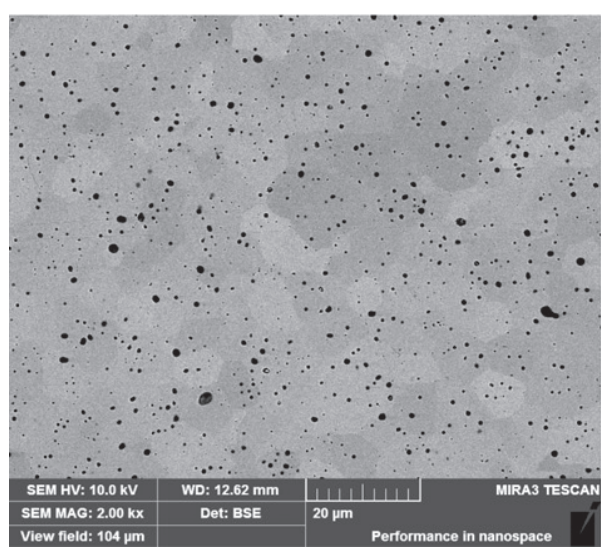

c)

Fig. 2. SEM images of polished surfaces of sample A (a), sample B (b) and sample C (c). 


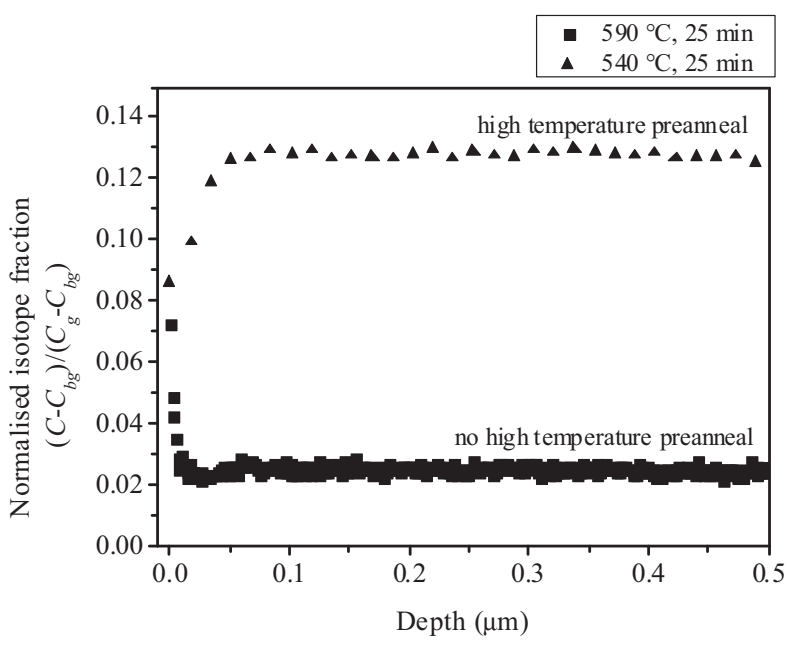

Fig. 3. Normalised oxygen isotope fraction as a function of depth of sample A exchanged for $25 \mathrm{~min}$ at $540{ }^{\circ} \mathrm{C}$ (with $900{ }^{\circ} \mathrm{C}$ pre-anneal) and $590{ }^{\circ} \mathrm{C}$ (without $900{ }^{\circ} \mathrm{C}$ pre anneal).

to be close to the natural isotope abundance. Recently it has been shown that carbonates with the general formula $(\mathrm{Ba}, \mathrm{Sr}) \mathrm{CO}_{3}$ form on the surface of BSCF5582 when exposed to a $\mathrm{CO}_{2}$-containing atmosphere, and drastically decrease the oxygen permeation flux through BSCF membranes [18] as well as the chemical surface exchange coefficient of oxygen of dense BSCF samples [19]. The decomposition of the surface carbonate in BSCF5582 was observed at temperatures higher than $800{ }^{\circ} \mathrm{C}[19]$. Several grains with darker contrast were observed by SEM (Fig. 4a) indicating the presence of lighter element(s) in the

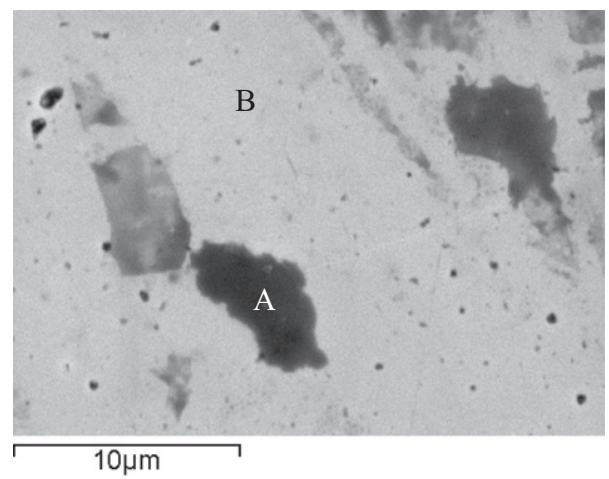

a)

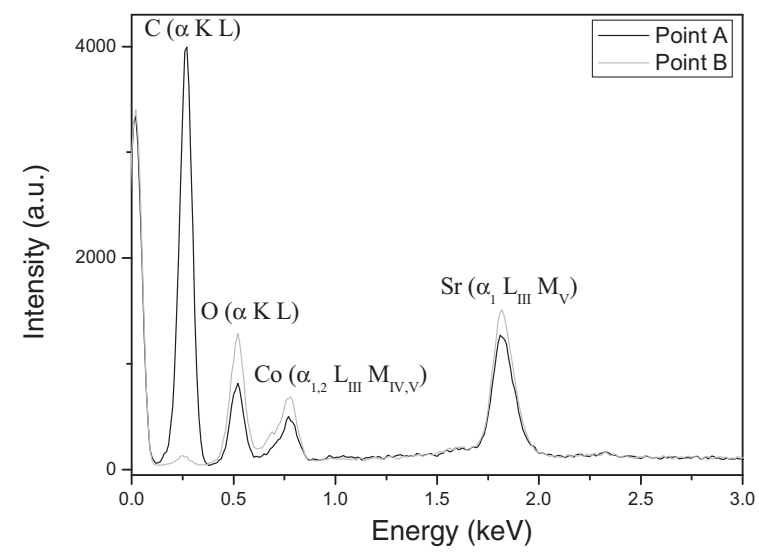

b)

Fig. 4. SEM image (a) and corresponding EDX spectra (b) of polished sample A made prior to oxygen exchange. analysed volume of the samples used in the preliminary experiments in the current study. A corresponding EDX spectrum confirms (Fig. 4b) the increased amount of carbon in the dark area as compared to the bright area. Furthermore, a peak with $\mathrm{m} / \mathrm{z}$ ratio of 12 was observed in the mass spectra collected during the SIMS analysis of the surface of the specimens (not shown) and was assigned to the presence of carbon-containing compounds in the region close to the surface. As a result a high temperature annealing $\left(900-950{ }^{\circ} \mathrm{C}\right.$ at 0.21 bar for samples $\mathrm{A}$ and $\mathrm{B}$, and $800{ }^{\circ} \mathrm{C}$ at $13.3 \times 10^{-3}$ bar for sample $\mathrm{C}$ ) was employed prior to the tracer exchange experiments in the reminder of this study in order to decompose any possible surface C-containing compounds. These high temperature pre-anneals enhanced ${ }^{18} \mathrm{O}$ incorporation in BSCF5582 (Fig. 3) and allowed the determination of tracer diffusion coefficients. At the same time a low ${ }^{18} \mathrm{O}$ fraction close to the sample surface was observed. Similarly, low values of the ${ }^{18} \mathrm{O}$ fraction close to the surface have been reported during oxygen diffusion depth profiling in polycrystalline $\mathrm{La}_{0.6} \mathrm{Sr}_{0.4} \mathrm{CoO}_{3}[20]$ and in epitaxial $\mathrm{La}_{2} \mathrm{NiO}_{4}+\delta$ thin films [21]. The reason for the observed depletion is currently unclear, but may be related to the segregation of constituent ions after high temperature pre-anneal, the reformation of the carbonate layer and/or back exchange of ${ }^{18} \mathrm{O}$ when exposed to the ambient atmosphere after the tracer exchange process.

Typical craters sputtered within individual BSCF5582 grains (sample A) are shown in Fig. 5a. Due to a relatively high incidence of closed pores (e.g. as marked by $\mathrm{X}$ in Fig. 5a), partially exposed pores were observed in several sputtered craters. Only craters with no detectable defects after sputtering (pores, grain boundaries) and having flat crater bottoms were used in the subsequent analysis to determine reliable ${ }^{18} \mathrm{O}$ concentration profiles. The effects of the sputtering parameters (time, current, area) on the crater depth are shown in Fig. 6. The following linear relationship between the crater depth and sputtering parameters was observed:

$d=\frac{0.01593 \times I}{S} \times t$

where $d$ is the crater depth ( $\mu \mathrm{m}), I-$ sputtering current (pA), $S-$ sputtering area $\left(\mu \mathrm{m}^{2}\right)$, and $t-$ sputtering time $(\mathrm{min})$. This relationship was used to convert sputtering time into the values of depth $(x)$ assuming constant values of sputtering current and area during the SIMS measurements.

Two types of feature were observed on the surface of sample A after the tracer exchanges (Fig. 5b). The first were particles of around $2-3 \mu \mathrm{m}$ (marked by S in Fig. 5b) and were located mostly at the grain boundaries and only occasionally within the grains. The result of EDX analysis of these inclusions showed higher concentration of $\mathrm{Ba}$ and $\mathrm{O}$ than in the bulk and additionally the presence of S. No sulphur was observed in EDX spectra collected from the other areas of the sample surface or the bulk (bottom of the sputtered crater). The atomic $\mathrm{Ba} / \mathrm{S}$ ratio is around 1 suggesting that these inclusions probably contain $\mathrm{BaSO}_{4}$ which is stable in air at $950{ }^{\circ} \mathrm{C}$ [22]. The origin of the $\mathrm{S}$ contamination is currently unclear. However it is possible to speculate that the segregation of $\mathrm{Ba}$ on the surface occurred during the high temperature pre-anneal at $950{ }^{\circ} \mathrm{C}$ followed by a transformation to $\mathrm{BaSO}_{4}$ when exposed to the unknown contaminant (presumably $\mathrm{SO}_{2}$ ) present in the ambient air. The formation of $\mathrm{SrSO}_{4}$ at the surface of $\mathrm{La}_{0.6} \mathrm{Sr}_{0.4} \mathrm{CoO}_{3}-\delta$ and $\mathrm{La}_{0.58} \mathrm{Sr}_{0.4} \mathrm{Co}_{0.2} \mathrm{Fe}_{0.8} \mathrm{O}_{3}{ }_{-\delta}$ in $\mathrm{SO}_{2}$-containing atmospheres via a similar mechanism has been reported in the literature $[23,24]$. The second type of feature were small highly crystalline particles (less than $0.6 \mu \mathrm{m}$ ) located randomly on the sample surface (Fig. 5c). The small size of the crystallites prevented the determination of their chemical composition by EDX, but relative increases in the $\mathrm{Co}$ and $\mathrm{Sr}$ concentrations were observed when the electron beam was within and near the crystallite. Similar small features (less than $0.2 \mu \mathrm{m}$ ) have been observed on the surface of epitaxial BSCF5582 films grown by PLD [25]. EDX analysis did not detect any impurities at the bottom of a sputtered crater 
on sample $A$ or on the surfaces of sample $C$. The measured compositions were $\mathrm{Ba}_{0.52} \mathrm{Sr}_{0.54} \mathrm{Co}_{0.80} \mathrm{Fe}_{0.20} \mathrm{O}_{3}-\delta$ (sample $\mathrm{A}$ ) and $\mathrm{Ba}_{0.49} \mathrm{Sr}_{0.51} \mathrm{Co}_{0.80} \mathrm{Fe}_{0.20} \mathrm{O}_{3}-\delta$ (sample $\mathrm{C}$ ).

Examples of a normalised oxygen tracer concentration profiles were measured by the IEDP within an individual grain of sample A exchanged at $435{ }^{\circ} \mathrm{C}$ for $14.3 \mathrm{~min}$, as well as the fits to the Eq. (1) are shown in Fig. 7a. The large scatter of the data within the individual depth profile is caused by the low ${ }^{18} \mathrm{O}$ fraction, the high background pressure in the FIB instrument and the low intensity of secondary ions when using a $\mathrm{Ga}^{+}$primary beam. The calculated values of $D_{b}{ }^{*}$ confirmed that $4 \sqrt{D_{b}{ }^{*} t}<l / 2$ for sample $A$ and hence the use of Eq. (1) were justified. A reasonable reproducibility of the calculated values of $D_{b}{ }^{*}$ and $k$ was observed $\left(D_{b}{ }^{*}=9.6 \times 10^{-10} \mathrm{~cm}^{2} \mathrm{~s}^{-1}, k=1.0 \times 10^{-8} \mathrm{~cm} \mathrm{~s}^{-1}\right.$ for depth profile $1, D_{b}{ }^{*}=11.6 \times 10^{-10} \mathrm{~cm}^{2} \mathrm{~s}^{-1}, k=1.1 \times 10^{-8} \mathrm{~cm} \mathrm{~s}^{-1}$ for depth

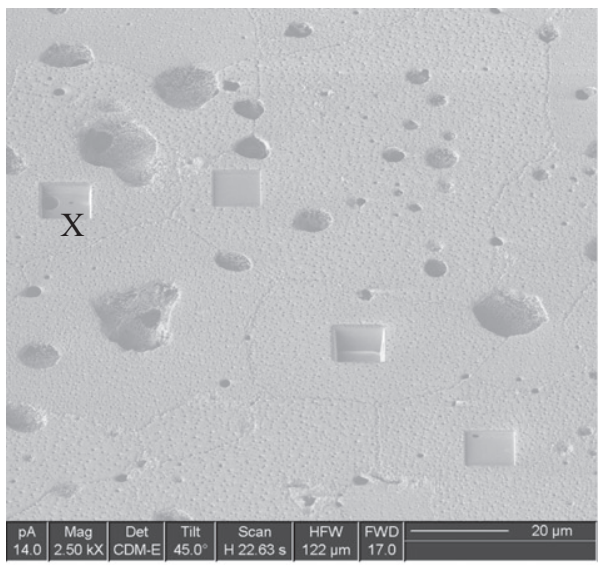

a)

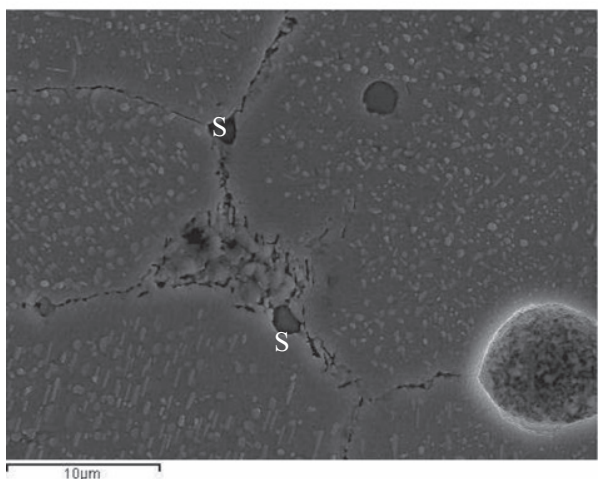

b)

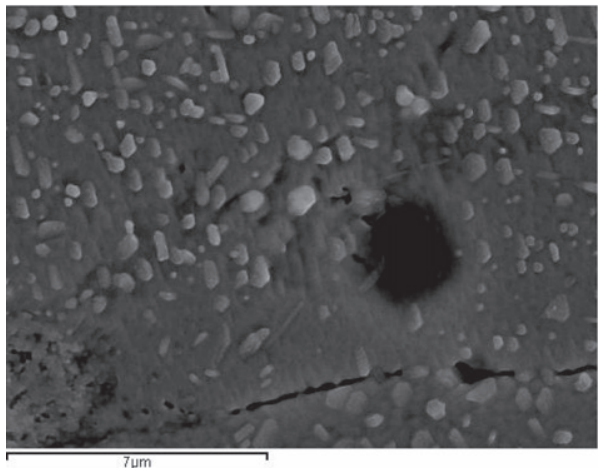

c)

Fig. 5. FIB secondary ion images of the sample A exchanged at $373^{\circ} \mathrm{C}$ for $30 \mathrm{~min}$ (a) and secondary electron images (b, c) of the specimen exchanged at $483^{\circ} \mathrm{C}$ for $7.9 \mathrm{~min}$.

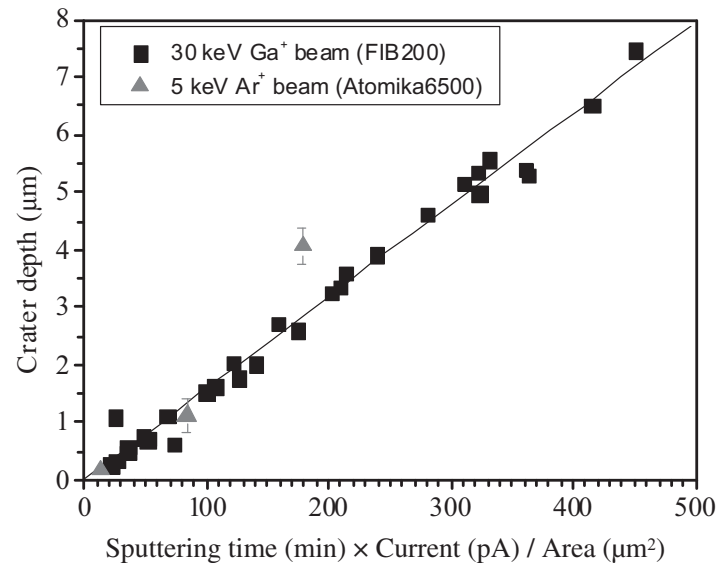

Fig. 6. Crater depth as a function of sputtering parameters (time, current, area). The black line is a linear fit to the plotted data.

profile 2 , and $D_{b}{ }^{*}=7.1 \times 10^{-10} \mathrm{~cm}^{2} \mathrm{~s}^{-1}, k=9.3 \times 10^{-9} \mathrm{~cm} \mathrm{~s}^{-1}$ for depth profile 3 in Fig. 7a) suggesting that the grain morphology and/or orientation have a weak effect on the oxygen diffusion in BSCF5582.
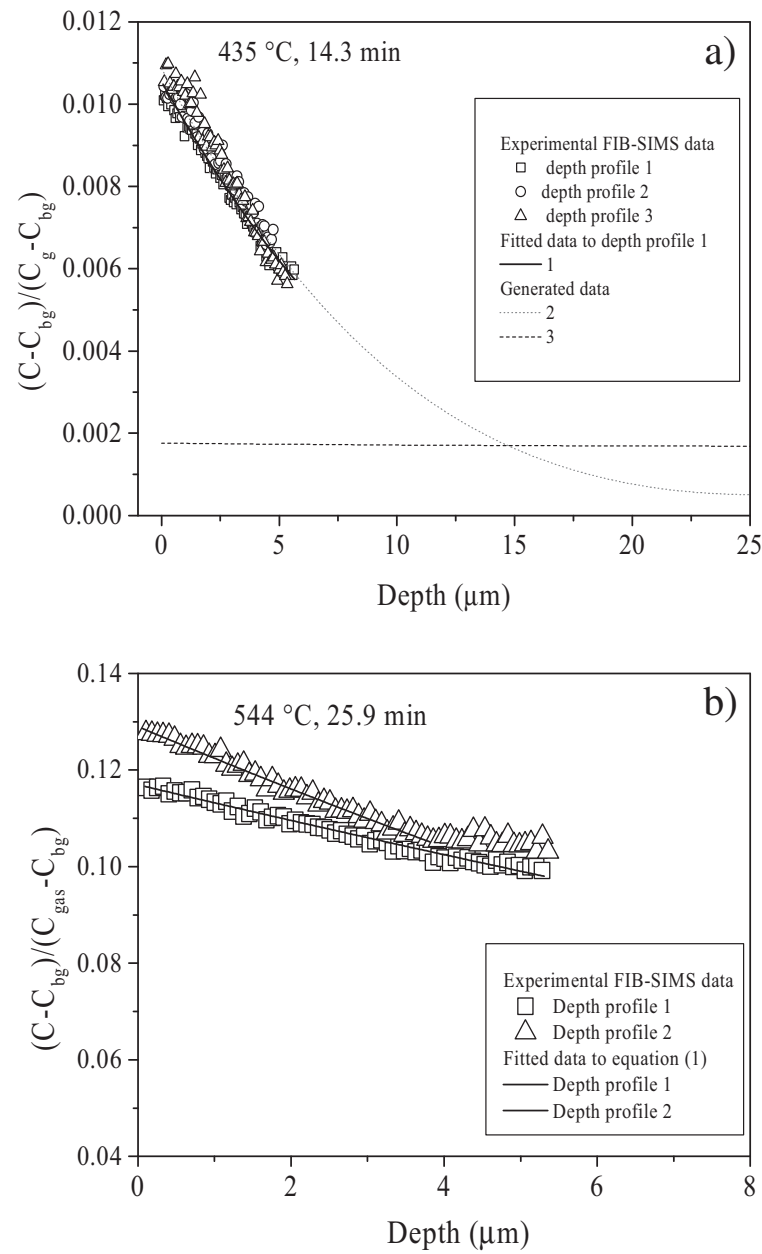

Fig. 7. Normalised ${ }^{18} \mathrm{O}$ isotope fraction as a function of sputtered depth for the sample $\mathrm{A}$ annealed for $14.3 \mathrm{~min}$ at $435{ }^{\circ} \mathrm{C}$ and $0.21 \mathrm{bar}$ (a). The black line 1 shows the fit to Eq. (1). The dashed line 2 shows the profile generated according to Eq. (2) $\left(D_{b}{ }^{*}=9.5 \times 10^{-10} \mathrm{~cm}^{2} \mathrm{~s}^{-1}\right.$, $k=1.0 \times 10^{-8} \mathrm{~cm} \mathrm{~s}^{-1}$, exchange time $=857 \mathrm{~s}$, thickness $\left.=0.005 \mathrm{~cm}\right)$. The dotted line 3 shows the profile generated according to Eq. (2) using the data of Wang et al. [27] $\left(D_{b}{ }^{*}=9 \times 10^{-8} \mathrm{~cm}^{2} \mathrm{~s}^{-1}, k=5.0 \times 10^{-8} \mathrm{~cm} \mathrm{~s}^{-1}\right.$, exchange time $=857 \mathrm{~s}$ thickness $=0.005 \mathrm{~cm})$. Normalised ${ }^{18} \mathrm{O}$ isotope fraction as a function of sputtered depth for the sample A annealed for $25.9 \mathrm{~min}$ at $544{ }^{\circ} \mathrm{C}$ and 0.21 bar (b). The black lines show the fits to Eq. (1). 
However sample A annealed at $544{ }^{\circ} \mathrm{C}$ for 25.9 min showed a significantly poorer reproducibility of the results $\left(D_{b}{ }^{*}=4.6 \times 10^{-9} \mathrm{~cm}^{2} \mathrm{~s}^{-1}, k=2.2\right.$ $\times 10^{-7} \mathrm{~cm} \mathrm{~s}^{-1}$ for depth profile 1 and $D_{b}{ }^{*}=2.8 \times 10^{-9} \mathrm{~cm}^{2} \mathrm{~s}^{-1}, k=$ $1.9 \times 10^{-7} \mathrm{~cm} \mathrm{~s}^{-1}$ for depth profile 2 in Fig. $7 \mathrm{~b}$ ) which may be caused by the presence of the hexagonal BSCF5582 phase as detected by XRD. The observation of slower oxygen kinetics in the hexagonal BSCF5582 phase as compared to the cubic one has been previously reported [26]. The normalised oxygen tracer concentration profile measured by the IELS along the cross-section of sample B, as well as the fit to the Eq. (2), is shown in Fig. 8.

Fig. 9 shows typical time dependence of the fractions of different isotope species $\left({ }^{18} \mathrm{O}_{2},{ }^{16} \mathrm{O}^{18} \mathrm{O}\right.$ and $\left.{ }^{16} \mathrm{O}_{2}\right)$ and the total fraction of the ${ }^{18} \mathrm{O}$ isotope in the gas phase during the isotope exchange experiment of sample $\mathrm{C}$, together with the fit to the Eq. (6). The ${ }^{18} \mathrm{O}$ exchange at $600{ }^{\circ} \mathrm{C}$ and 0.013 bar was repeated several times during the GPA experiments. Good reproducibility of the measured $D_{b}{ }^{*}$ and $k$ values suggested that no significant formation of hexagonal BSCF occurred during the prolonged anneals at low oxygen partial pressures. The calculated values of $D_{b}{ }^{*}$ and $k$ are given in Table 2 and the Arrhenius plots of $D_{b}{ }^{*}$ and $k$ are shown in Figs. 10 and 11, respectively.

A significant difference in the measured values of $D_{b}{ }^{*}$ was observed between samples $\mathrm{A}$ and $\mathrm{B}$. The values of $D_{b}{ }^{*}$ as determined by the IELS on sample $B$ are about two orders of magnitude higher than those measured within the individual grains of sample A by the IEDP. The results obtained on sample $A$ are in a good agreement with the values of $D_{b}{ }^{*}$ estimated from the chemical diffusion coefficients measured by the conductivity relaxation technique on the same sample [5] (Fig. 10). At the same time the values of $D_{b}{ }^{*}$ measured on sample B agree reasonably well with the results of an oxygen tracer diffusion study in BSCF5582 thin films epitaxially grown on a MgO substrate [27] and $D_{b}{ }^{*}$ estimated from the parameters of the oxygen chemical diffusion measured by the conductivity relaxation at temperatures higher than $700{ }^{\circ} \mathrm{C}[28]$. The observed difference in the values of $D_{b}{ }^{*}$ measured on sample A and B is discussed now in more detail.

One potential problem with analysing diffusion in an individual grain is that short circuit pathways around the grain might cause diffusion into the analysed volume from the back of the selected grain. In order to check the applicability of Eq. (1), derived for a semi-infinite medium, to the fitting of data obtained during sputtering of a $50 \mu \mathrm{m}$ grain, we generated a diffusion profile using Eq. (2) for diffusion within a finite sheet of $50 \mu \mathrm{m}$ thickness (grain size of sample A). A good agreement with Eq. (1) is still observed over the analysed depth (line 2 in Fig. 7) thus confirming that Eq. (1) can be used for fitting data obtained within the individual grains of the sample A. In addition we also generated a diffusion profile according to Eq. (2) but using the data of Wang et al. [27] which showed poor agreement with the experimentally

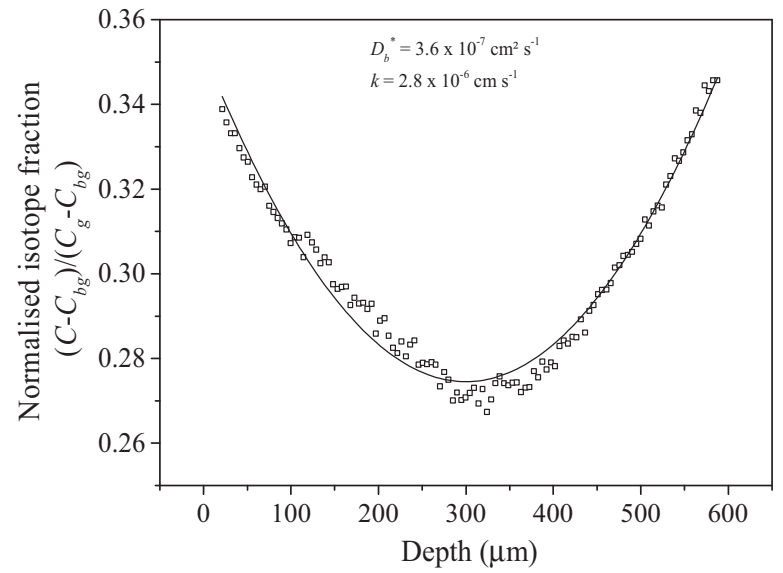

Fig. 8. Normalised ${ }^{18} \mathrm{O}$ isotope fraction as a function of position from line scan of sample $\mathrm{B}$ (thickness $577 \mu \mathrm{m}$ ). The sample was annealed at $594{ }^{\circ} \mathrm{C}$ and 0.21 bar for $68 \mathrm{~min}$. The black line shows the fit to Eq. (2).

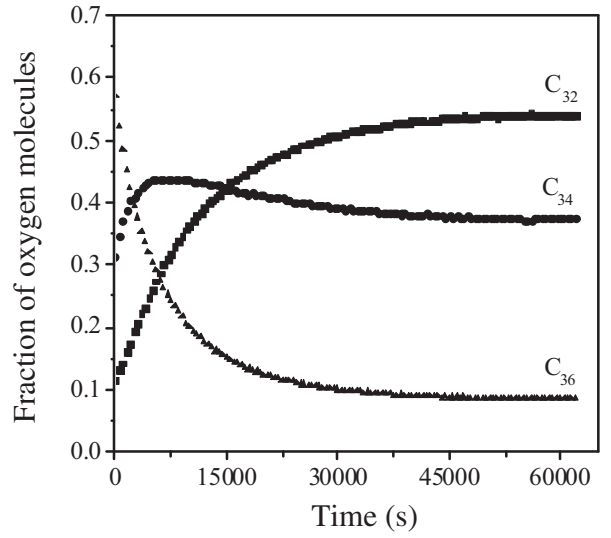

a)

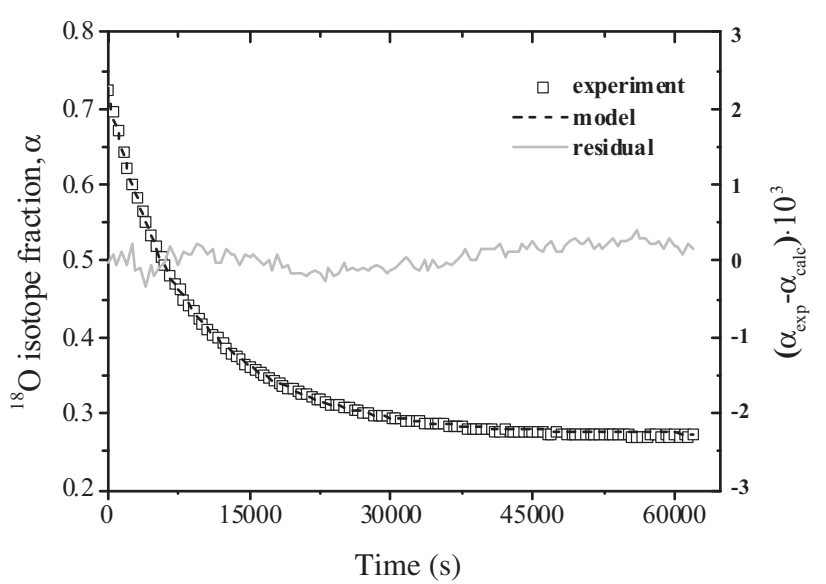

b)

Fig. 9. Time dependencies of (a) concentrations of different oxygen molecules $\left({ }^{18} \mathrm{O}_{2}\right.$, ${ }^{16} \mathrm{O}^{18} \mathrm{O}$ and ${ }^{16} \mathrm{O}_{2}$ ) and (b) ${ }^{18} \mathrm{O}$-fraction in the gas phase in a typical GPA isotope exchange experiment on sample $\mathrm{C}$ at $\mathrm{pO}_{2}=10^{-2}$ bar and $T=600{ }^{\circ} \mathrm{C}$. The discrepancy between the experimental and calculated ${ }^{18} \mathrm{O}$-isotope fraction $(\alpha)$ is shown as well.

observed data (Fig. 10). The calculated critical length $L_{C}=D_{b}{ }^{*} / k$ for sample A $(0.02-0.04 \mathrm{~cm})$ is below the sample thickness whereas $L_{C}$ for sample B $(2-0.12 \mathrm{~cm})$ is greater than the sample dimensions. Therefore significant errors can be expected during the simultaneous determination of $D_{b}{ }^{*}$ and $k$ in sample B [29]. As a result we suggest that the most reliable values of $D_{b}{ }^{*}$ were obtained for the individual grains in sample A using the IEDP technique. The higher diffusivity measured on sample B is likely to be related to defects in sample B (e.g. pores) which could provide alternative pathways with high oxygen mobility and influence tracer distribution along the longer penetration depths analysed by the IELS. It should be noted that small columnar grains were observed in epitaxial BSCF5582 films [27] which may have resulted in a larger contribution of diffusion along the grain boundaries in the overall process of oxygen transport in those samples. However the values of $D_{b}{ }^{*}$ in BSCF5582 (sample A) are at least approximately 3 orders of magnitude larger than those in other promising SOFC cathodes at intermediate temperatures $\left(<500{ }^{\circ} \mathrm{C}\right)$, like for example $\mathrm{La}_{0.6} \mathrm{Sr}_{0.4} \mathrm{Fe}_{0.8} \mathrm{Co}_{0.2} \mathrm{O}_{3}-\delta$ (LSCF) [30], $\mathrm{La}_{0.6} \mathrm{Sr}_{0.4} \mathrm{CoO}_{3}$ (LSC64) [20], $\mathrm{La}_{0.5} \mathrm{Sr}_{0.5} \mathrm{CoO}_{3}$ (LSC55) [31], and $\mathrm{La}_{0.75} \mathrm{Sr}_{0.25} \mathrm{FeO}_{3}$ (LCF) [32].

The data for $k$ (Fig. 11) of the studied samples A, B and C agree within one order of magnitude with each other as well as with the results from the literature $[5,6,27]$. It should be noted that the data of Bouwmeester et al. [6] were measured on sample $C$ by a pulsed isotope exchange technique (PIE). The relatively minor variability could indicate that the errors in the determination of the surface exchange coefficients resulted from the observed depletion of the ${ }^{18} \mathrm{O}$ concentration on the surface 
Table 2

Parameters of ${ }^{18} \mathrm{O}$ tracer diffusion in $\mathrm{Ba}_{0.5} \mathrm{Sr}_{0.5} \mathrm{Co}_{0.8} \mathrm{Fe}_{0.2} \mathrm{O}_{3}-{ }_{\delta}$ calculated from the IEDP (sample A), IELS (sample B) and GPA (sample C). *The standard deviation is not provided as less than 3 experiments were performed at those conditions.

\begin{tabular}{|c|c|c|c|}
\hline Sample & Condition of ${ }^{18} \mathrm{O}$ exchange & $D_{b}^{*}\left(\mathrm{~cm}^{2} \mathrm{~s}^{-1}\right)$ & $k\left(\mathrm{~cm} \mathrm{~s}^{-1}\right)$ \\
\hline A & $311{ }^{\circ} \mathrm{C}, 0.21$ bar, $20.4 \mathrm{~min}$ & $(2.7 \pm 0.3) \times 10^{-10}$ & $(9.3 \pm 1.2) \times 10^{-9}$ \\
\hline A & $373^{\circ} \mathrm{C}, 0.21$ bar, $30.7 \mathrm{~min}$ & $(3.5 \pm 1.1) \times 10^{-10}$ & $(3.8 \pm 0.6) \times 10^{-9}$ \\
\hline A & $435^{\circ} \mathrm{C}, 0.21$ bar, $14.3 \mathrm{~min}$ & $(9.5 \pm 2.3) \times 10^{-10}$ & $(1.0 \pm 0.1) \times 10^{-8}$ \\
\hline A & $483^{\circ} \mathrm{C}, 0.21$ bar, $7.9 \mathrm{~min}$ & $(1.6 \pm 0.9) \times 10^{-9}$ & $(4.1 \pm 2.2) \times 10^{-8}$ \\
\hline A & $544^{\circ} \mathrm{C}, 0.21$ bar, $25.9 \mathrm{~min}$ & $4.6 \times 10^{-9 *}$ & $2 \times 10^{-7 *}$ \\
\hline B & $444^{\circ} \mathrm{C}, 0.21 \mathrm{bar}, 877 \mathrm{~min}$ & $(1.2 \pm 0.3) \times 10^{-7}$ & $(6.0 \pm 0.5) \times 10^{-8}$ \\
\hline B & $594{ }^{\circ} \mathrm{C}, 0.21$ bar, $68 \mathrm{~min}$ & $3.6 \times 10^{-7 *}$ & $2.8 \times 10^{-6 *}$ \\
\hline C & $700{ }^{\circ} \mathrm{C}, 13.6 \times 10^{-3} \mathrm{bar}$ & $(4.1 \pm 0.2) \times 10^{-7}$ & $(1.5 \pm 0.1) \times 10^{-6}$ \\
\hline C & $700{ }^{\circ} \mathrm{C}, 10.7 \times 10^{-3}$ bar & $(4.2 \pm 0.2) \times 10^{-7}$ & $(1.1 \pm 0.1) \times 10^{-6}$ \\
\hline C & $700{ }^{\circ} \mathrm{C}, 8.0 \times 10^{-3} \mathrm{bar}$ & $(4.4 \pm 0.2) \times 10^{-7}$ & $(8.4 \pm 0.1) \times 10^{-7}$ \\
\hline C & $700{ }^{\circ} \mathrm{C}, 5.3 \times 10^{-3} \mathrm{bar}$ & $(4.4 \pm 0.2) \times 10^{-7}$ & $(5.2 \pm 0.1) \times 10^{-7}$ \\
\hline C & $700{ }^{\circ} \mathrm{C}, 2.7 \times 10^{-3} \mathrm{bar}$ & $(4.0 \pm 0.2) \times 10^{-7}$ & $(2.7 \pm 0.1) \times 10^{-7}$ \\
\hline C & $750{ }^{\circ} \mathrm{C}, 6.7 \times 10^{-3} \mathrm{bar}$ & $(4.1 \pm 0.2) \times 10^{-7}$ & $(1.0 \pm 0.1) \times 10^{-6}$ \\
\hline C & $650{ }^{\circ} \mathrm{C}, 6.7 \times 10^{-3} \mathrm{bar}$ & $(4.5 \pm 0.4) \times 10^{-8}$ & $(5.2 \pm 0.1) \times 10^{-7}$ \\
\hline C & $550{ }^{\circ} \mathrm{C}, 6.7 \times 10^{-3} \mathrm{bar}$ & $(2.2 \pm 0.3) \times 10^{-8}$ & $(6.3 \pm 0.2) \times 10^{-8}$ \\
\hline C & $600{ }^{\circ} \mathrm{C}, 13.3 \times 10^{-3}$ bar & $(5.2 \pm 0.4) \times 10^{-8}$ & $(2.5 \pm 0.1) \times 10^{-7}$ \\
\hline C & $600{ }^{\circ} \mathrm{C}, 1.0 \times 10^{-3} \mathrm{bar}$ & $(4.4 \pm 0.3) \times 10^{-8}$ & $(2.0 \pm 0.1) \times 10^{-7}$ \\
\hline C & $600^{\circ} \mathrm{C}, 7.5 \times 10^{-3} \mathrm{bar}$ & $(3.9 \pm 0.3) \times 10^{-8}$ & $(1.3 \pm 0.1) \times 10^{-7}$ \\
\hline C & $600^{\circ} \mathrm{C}, 4.7 \times 10^{-3} \mathrm{bar}$ & $(4.1 \pm 0.3) \times 10^{-8}$ & $(7.9 \pm 0.2) \times 10^{-8}$ \\
\hline C & $600^{\circ} \mathrm{C}, 2.7 \times 10^{-3} \mathrm{bar}$ & $(5.2 \pm 0.5) \times 10^{-8}$ & $(5.1 \pm 0.2) \times 10^{-8}$ \\
\hline C & $800{ }^{\circ} \mathrm{C}, 14.7 \times 10^{-3}$ bar & $(5.6 \pm 0.2) \times 10^{-7}$ & $(2.6 \pm 0.1) \times 10^{-6}$ \\
\hline C & $800^{\circ} \mathrm{C}, 8.7 \times 10^{-3} \mathrm{bar}$ & $(6.5 \pm 0.2) \times 10^{-7}$ & $(1.6 \pm 0.1) \times 10^{-6}$ \\
\hline C & $800^{\circ} \mathrm{C}, 7.5 \times 10^{-3} \mathrm{bar}$ & $(6.8 \pm 0.2) \times 10^{-7}$ & $(1.4 \pm 0.1) \times 10^{-6}$ \\
\hline C & $800^{\circ} \mathrm{C}, 5.4 \times 10^{-3} \mathrm{bar}$ & $(6.5 \pm 0.2) \times 10^{-7}$ & $(1.0 \pm 0.1) \times 10^{-6}$ \\
\hline C & $800^{\circ} \mathrm{C}, 3.1 \times 10^{-3}$ bar & $(7.4 \pm 0.1) \times 10^{-7}$ & $(5.8 \pm 0.2) \times 10^{-7}$ \\
\hline C & $800^{\circ} \mathrm{C}, 1.3 \times 10^{-3}$ bar & $(7.3 \pm 0.1) \times 10^{-7}$ & $(2.4 \pm 0.1) \times 10^{-7}$ \\
\hline
\end{tabular}

layer. Interestingly, the surface exchange coefficients for BSCF5582 and LSCF are of comparable magnitude. The estimated values for the activation energies for $D_{b}{ }^{*}$ and $k$ measured within the individual grains of sample A are $0.72 \pm 0.05$ and $1.10 \pm 0.15 \mathrm{eV}$, respectively. This low value of $0.72 \mathrm{eV}$ is responsible for the large differences in $D_{b}{ }^{*}$ value between BSCF5582 and LSCF6482 in the temperature range below $500{ }^{\circ} \mathrm{C}$.

The oxygen partial pressure dependencies of $D_{b}{ }^{*}$ and $k$ were measured on sample $C$ and are shown in Figs. 12 and 13, respectively. The oxygen partial pressure dependence of $D_{b}{ }^{*}$ is weak, with slight increase of $D_{b}{ }^{*}$ when the oxygen partial pressure decreased at 700

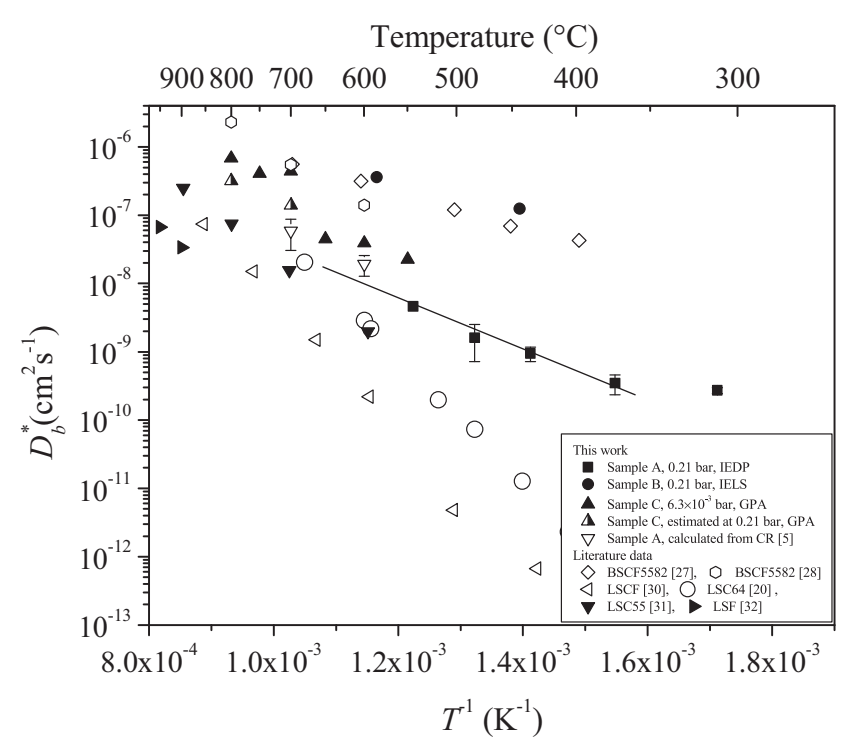

Fig. 10. Arrhenius plot of $D_{b}{ }^{*}$ in BSCF5582 measured by different methods. The solid line is the guide to the eye. Data for $\mathrm{La}_{0.6} \mathrm{Sr}_{0.4} \mathrm{Fe}_{0.8} \mathrm{CO}_{0.2} \mathrm{O}_{3}-\delta$ (LSCF) are given for comparison [30].

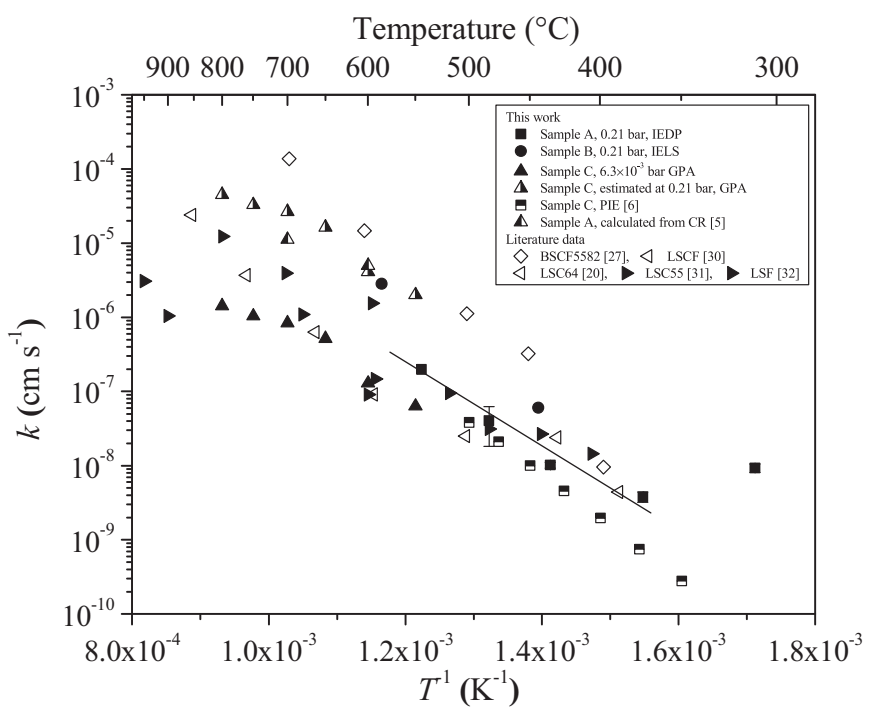

Fig. 11. Arrhenius plot of $k$ in BSCF5582 measured by different methods. The solid line is the guide to the eye. Data for $\mathrm{La}_{0.6} \mathrm{Sr}_{0.4} \mathrm{Fe}_{0.8} \mathrm{Co}_{0.2} \mathrm{O}_{3}-\delta$ (LSCF) are given for comparison [30].

and $800{ }^{\circ} \mathrm{C}$. This is most likely due to an increase in the concentration of oxygen vacancies when the oxygen non-stoichiometry $(\delta)$ in $\mathrm{Ba}_{0.5} \mathrm{Sr}_{0.5} \mathrm{Co}_{0.8} \mathrm{Fe}_{0.2} \mathrm{O}_{3}-{ }_{-}$increased (inset in Fig. 12). The linear extrapolation of the dependence of $D_{b}{ }^{*}$ with $\mathrm{pO}_{2}$ at $800{ }^{\circ} \mathrm{C}$ allowed us to estimate the values of tracer diffusion coefficients for sample $\mathrm{C}$ at 0.21 bar. The diffusivities for sample $C$ are intermediate to the data for sample A and sample B (Fig. 10). This could be due to the fact that the grain size and/or extent of the porosity for sample $C$ are between the ones for samples A and B (Table 1 ). The activation energies for $D_{b}{ }^{*}$ and $k$ at $6.7 \times 10^{-3}$ bar are $1.15 \pm 0.21$ and $0.99 \pm 0.12 \mathrm{eV}$, respectively, for sample $C$ at $6.7 \times 10^{-3}$ bar. The difference in the values of the activation energies between samples $A$ and $C$ might be related to the variation of defect concentrations with $\mathrm{pO}_{2}$. For example, at $600{ }^{\circ} \mathrm{C}$ Chen at al. [28] observed that the oxygen partial pressure dependence of electrical conductivity exhibited a change in slope at around 0.01 bar.

The values of $k$, in contrast to the values of $D_{b}{ }^{*}$, exhibit a strong dependence on $\mathrm{pO}_{2}$ (Fig. 13) as follows

$k \propto \mathrm{pO}_{2}^{n}$

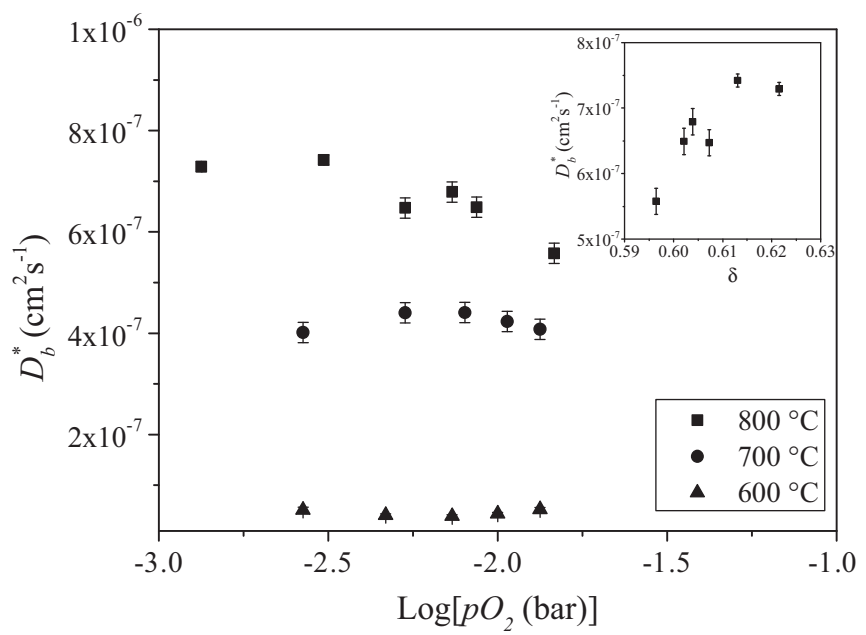

Fig. 12. Oxygen partial pressure dependence of $D_{b}{ }^{*}$ in BSCF5582 (sample C) measured by the GPA technique. Inset shows the effect of oxygen non-stoichiometry ( $\delta$ ) in BSCF5582 on $D_{b}{ }^{*}$ at $800{ }^{\circ} \mathrm{C}$. 


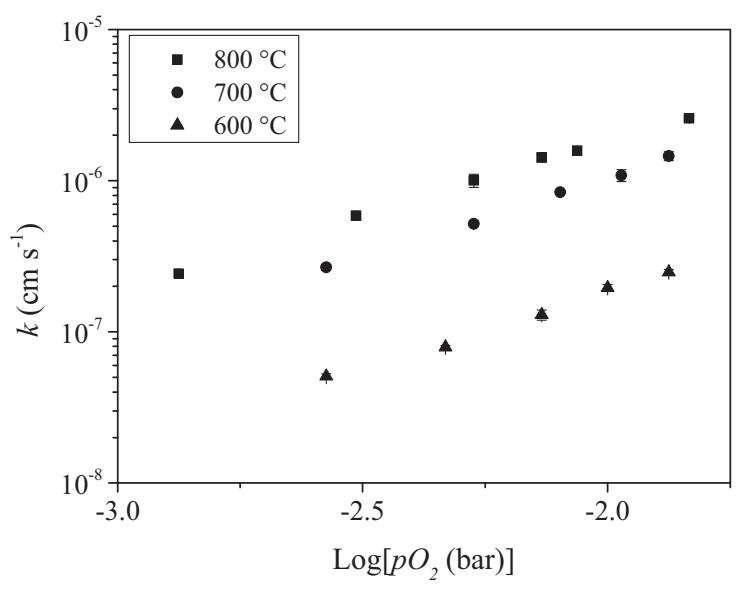

Fig. 13. Oxygen partial pressure dependence of $k$ in BSCF5582 (sample C) measured by the GPA technique.

in which the power $n$ of the dependence on $\mathrm{pO}_{2}$ is close to 1 at all temperatures. The power $n$ can range from -1 to 1 depending on the type of adsorbed species, their charge, and coverage [33]. Since the power $n$ can be dependent on the oxygen partial pressure it is very difficult to extrapolate $\mathrm{pO}_{2}$-dependencies of $k$ from the data measured under low oxygen pressures of the GPA measurements to 0.21 bar for comparison with $k$ measured by the depth profiling technique. Nevertheless, a good agreement between the $k$ values at $\mathrm{pO}_{2}=0.21$ bar obtained from the PIE [6], IEDP, IELS techniques and GPA recalculated to the same oxygen pressure assuming $n \sim 1$ is observed (Fig. 10).

\section{Conclusions}

Oxygen surface exchange in $\mathrm{Ba}_{0.5} \mathrm{Sr}_{0.5} \mathrm{Co}_{0.8} \mathrm{Fe}_{0.2} \mathrm{O}_{3}-\delta$ was hindered by a passivating surface layer (probably carbonate). Fast bulk diffusion and surface exchange were observed at the temperature range of $310-800{ }^{\circ} \mathrm{C}$ and over a range of oxygen partial pressures $\left(1.3 \times 10^{-3}\right.$ 0.21 bar). The activation energies for oxygen tracer diffusion and surface exchange at 0.21 bar were $0.72 \pm 0.05$ and $1.10 \pm 0.15 \mathrm{eV}$, respectively. The tracer diffusion coefficient showed weak dependence upon oxygen partial pressure, whereas the surface exchange coefficient exhibited strong oxygen partial pressure dependence. The morphology of the studied samples (especially the porosity and the grain size) had a profound effect on the tracer diffusion coefficient.

\section{Acknowledgements}

Financial support from the European Commission within the integrated project SOFC600 (contract no. 020089) is gratefully acknowledged. Parts of this work are financially supported by the grant of RFBS \# 13-03-00519 and the Federal Target Program \# 20121.5-14-000-2019-002-8888. GPA isotope exchange measurements were done using facilities of the Shared Access Centre "Composition of Compounds" at the Institute of High Temperature Electrochemistry, Russia.

\section{References}

[1] Z. Shao, S.M. Haile, Nature 431 (2004) 170.

[2] S. McIntosh, J.F. Vente, W.G. Haije, D.H. Blank, H.J.M. Bouwmeester, Solid State Ionics 177 (2006) 1737.

[3] J.A. Kilner, R.A. De Souza, Proc. 17th Risø International Symposium on "High Temperature Electrochemistry: Ceramics and Metals", Risø National Laboratory, Denmark, 1996, p. 41.

[4] M. Arnold, J. Martynczuk, K. Efimov, H. Wang, A. Feldhoff, J. Membr. Sci. Inorg. Hybrid Membr. 316 (2008) 137.

[5] E. Bucher, A. Egger, P. Ried, W. Sitte, P. Holtappels, Solid State Ionics 179 (2008) 1032.

[6] H.J.M. Bouwmeester, C. Song, J. Zhu, J. Yi, M.S. Annaland, B.A. Boukamp, Phys. Chem. Chem. Phys. 11 (2009) 9640.

[7] A.C. Larson, R.B. Von Dreele, Los Alamos National Laboratory Report LAUR 86-748, 2000.

[8] M.V. Ananyev, E.Kh. Kurumchin, Russ. J. Phys. Chem. A 84 (6) (2010) 1039.

[9] R.A. De Souza, Ionic transport in acceptor-doped perovskites(PhD. Thesis) University of London, London, 1996.

[10] R.A. De Souza, R.J. Chater, Solid State Ionics 176 (2005) 1915.

[11] J. Crank, The Mathematics of Diffusion, Second edition Oxford Univ. Press, New York, 1975.

[12] R.J. Chater, D.S. McPhail, Appl. Surf. Sci. 231-232 (2004) 834.

[13] D.R. Killoran, J. Electrochem. Soc. 109 (1962) 170.

[14] K. Klier, E. Kucera, J. Phys. Chem. Solids 27 (1966) 1087

[15] R. Kriegel, R. Kircheisen, J. T pfer, Solid State Ionics 181 (2010) 64.

[16] P. Ried, E. Bucher, W. Preis, W. Sitte, P. Holtappels, ECS Trans. 7 (2007) 1217.

[17] S. Svarcova, K. Wiik, J. Tolchard, H.J.M. Bouwmeester, Solid State Ionics 178 (2008) 1787.

[18] M. Arnold, H. Wang, A. Feldhoff, J. Membr. Sci. 293 (2007) 44

[19] E. Bucher, A. Egger, G.B. Caraman, W. Sitte, J. Electrochem. Soc. 155 (2008) B1218.

[20] A.V. Berenov, A. Atkinson, J.A. Kilner, E. Bucher, W.A. Sitte, Solid State Ionics 181 (2010) 819.

[21] M. Burriel, G. Garcia, J. Santiso, J.A. Kilner, R.J. Chater, S.J. Skinner, J. Mater. Chem. 18 (2008) 416.

[22] M. Ishihara, H. Matsui, G. Hashizume, J. Therm. Anal. Calorim. 38 (1992) 1801.

[23] E. Bucher, C. Gspan, F. Hofer, W. Sitte, Solid State Ionics 238 (2013) 15

[24] E. Bucher, C. Gspan, F. Hofer, W. Sitte, Solid State Ionics 230 (2013) 7.

[25] M. Burriel, C. Niedrig, W. Menesklou, S. Wagner, J. Santiso, E. Ivers-Tiffée, Solid State Ionics 181 (2010) 602

[26] S. Yakovlev, C.-Y. Yoo, S. Fang, H.J.M. Bouwmeester, Appl. Phys. Lett. 96 (2010) 254101.

[27] L. Wang, R. Merkle, J. Maier, T. Acarturk, U. Starke, Appl. Phys. Lett. 94 (2009) 071908.

[28] D. Chen, Z. Shao, Int. J. Hydrog. Energy 36 (2011) 6948.

[29] B.C.H. Steele, Solid State Ionics 134 (2000) 3.

[30] S.J. Benson, R.J. Chater, J.A. Kilner, Proc. 3rd International Symposium on Ionic and Mixed Conducting Ceramics, The Electrochemical Society, Paris, 1997, p. 596.

[31] R.A. De Souza, R.A.J.A. Kilner, Solid State Ionics 106 (1998) 175.

[32] T. Ishigaki, S. Yamauchi, K. Kishio, J. Mizusaki, K. Fueki, Kazuo, J. Solid State Chem. 73 (1988) 179.

[33] J. Fleig, R. Merkle, J. Maier, Phys. Chem. Chem. Phys. 9 (2007) 2713. 